\title{
Lateral Contrast Study on Road Performance of SMA-13 under Different Fiber Content
}

\author{
YanHai Yang ${ }^{1, ~ a, ~ D o n g ~ Z h a n g ~}{ }^{2, b}$, WangKui Bian ${ }^{3, c}$ and Ye Yang ${ }^{4, d}$ \\ ${ }^{1}$ Hunnan New District, Shenyang City, Liaoning Hunnan East Road on the 9th Shenyang University \\ of Architecture , China \\ ayangyanhai168@126.com, b403152902@qq.com, ${ }^{c} 1548096298 @ q q . c o m$, \\ yangye138@126.com
}

\section{Keywords: Road Engineering; SMA-13; Road Performance; Fibers; Mix Design}

Abstract. The high temperature rutting test, the Marshall test, the low temperature bending test, the water stability test and the scatter spatter test of SMA-13 asphalt mixture were carried out based on the raw material and the mix design. The lateral comparison of SMA-13 road performance was carried out for wood fibers and mineral fibers with different dosage. The results showed that SMA-13 asphalt mixture with wood fiber had the best oil absorption and road performance. According to the three kinds of mineral fibers (mineral 2, mineral 3 and mineral 4) used in the paper, the mineral of No.3 mineral fiber has better oil absorption and road performance.

\section{Introduction}

Stone Matrix Asphalt (SMA) is a discontinuous graded asphalt mixture filled with asphalt mastic comprised of asphalt, fiber stabilizers, mineral dust, and small fine aggregates in the interstices formed by the coarse aggregate material. Mineral fiber is a kind of green non-metallic inorganic mineral fibers, compared to other organic fibers (wood and polymer fibers), have higher strength and better resistance to high temperature and water absorption performance. Mineral fiber can improve aging and oxidation resistance of asphalt pavement and prolong the service life of the road, which is one of the effective ways to solve heavy-haul traffic on highways ${ }^{[1-4]}$.

At present, wood fiber, polymer fiber and mineral fiber are the most commonly used three kinds of fibers in SMA. Many scholars had studied the influence of these three kinds of fiber on asphalt mixture and compared their different road performance. In this paper, three kinds of different mineral fibers (named as mineral No.2, mineral No.3 and mineral No.4) and wood fiber were selected for the road performance comparison test of SMA-13 asphalt mixture, the effect of different fibers on the performance of SMA-13 asphalt mixture was analyzed.

\section{SMA-13 Mix Design}

\section{Raw Materials}

Coarse aggregate selects basalt, which specifications are 5.6 8.0mm, 8.0 11.4mm, 11.4 16mm, Fine aggregate selects limestone, which specifications are $0 \sim 1.18 \mathrm{~mm}, 1.1 \sim 2.36 \mathrm{~mm}, 2.36 \sim 4.75 \mathrm{~mm}$, SBS modified asphalt was chosen to use, The results of slag test meet the test requirements, the wood fiber and mineral fiber used in this test were tested in accordance with the Technical Specifications for Construction of Highway Asphalt Pavement (JTG F40-2004), Those indicators meet the technical requirements Mineral Composition

SMA-13 asphalt mixture additive proportion of each mineral: $11.4 \sim 16 \mathrm{~mm}$ is $22 \%, 8 \sim 11.4 \mathrm{~mm}$ is $32 \%$, $5.6 \sim 8 \mathrm{~mm}$ is $24 \%, 1.18 \sim 2.36 \mathrm{~mm}$ is $3 \%, 0 \sim 1.18 \mathrm{~mm}$ is $9 \%$ Mineral powder is $10 \%$ Optimum Determination of the best oil asphalt-aggregate ratio

In accordance with the relevant provisions of "Technical Specifications for Construction of Highway Asphalt Pavement" (JTG F40-2004), through consulting a large number of literature, the optimum dosage of various fibers was determined. The content of wood fiber was $0.3 \%$, and the content of three 
kinds of mineral fiber was $0.4 \%^{[5-6]}$. The Marshall test was used to determine the best oil asphalt-aggregate ratio of various types of fibers The results are shown in Table 1.

Tab.1 Different fiber content of the best oil asphalt-aggregate ratio

\begin{tabular}{c|c|c|c|c|c|c|c|c|c|c}
\hline Fiber type & Wood fiber & \multicolumn{3}{|c|}{ No.2 mineral fiber } & \multicolumn{3}{c|}{ No.3 mineral fiber } & \multicolumn{3}{c}{ No.4 mineral fiber } \\
\hline Fiber content $(\%)$ & 0.3 & 0.3 & 0.4 & 0.5 & 0.3 & 0.4 & 0.5 & 0.3 & 0.4 & 0.5 \\
\hline Whetstone ratio(\%) & 6.75 & 6.50 & 6.57 & 6.60 & 6.50 & 6.65 & 6.77 & 6.46 & 6.55 & 6.59 \\
\hline
\end{tabular}

\section{Road Performance of SMA-13 Asphalt Mixture}

\section{High Temperature Rutting Test}

The stability of asphalt mixture was assessed by using the dynamic stability index. The high temperature rutting test of SMA-13 asphalt mixture was carried out under the condition of the best oil asphalt-aggregate ratio $^{[7]}$. Four groups of rutting tests were made on different fibers at different dosages. The test results were averaged.The results are shown in Fig.1.

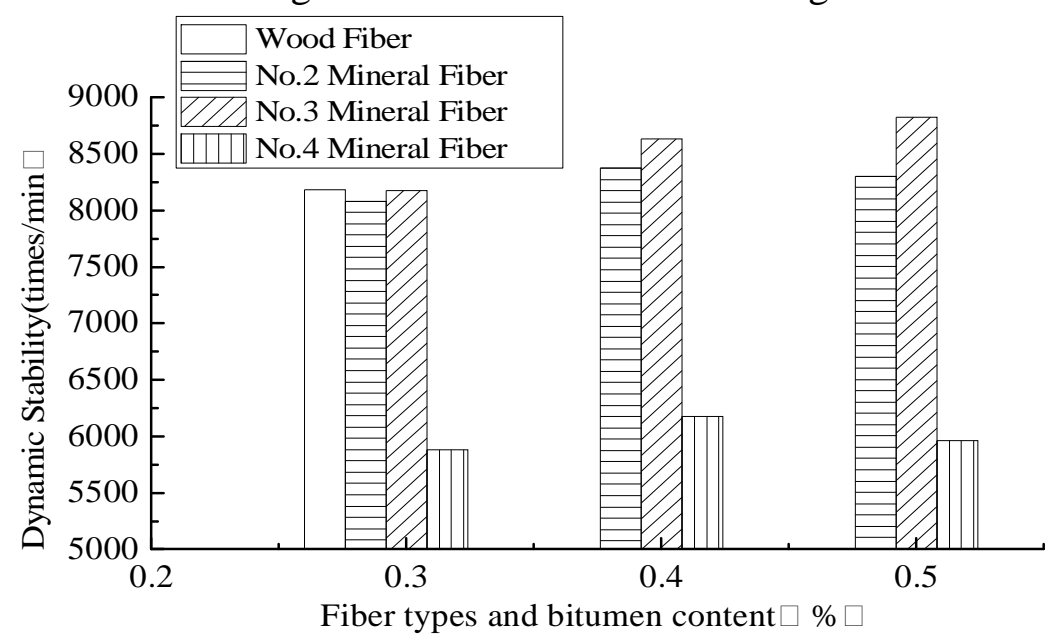

Fig.1 SMA-13 rutting test results

From the analysis of the test results in Fig.1, the horizontal comparison of three mineral fibers can be concluded that, under the same fiber content, the rutting stability of the asphalt mixture with mineral 3 is the most stable, the high temperature stability is the best. In a certain range, the dynamic stability of rutting of asphalt mixture is continuously increasing with the increase of the fiber content of mineral No. 2 and No.4, and the dynamic stability reaches the peak when the fiber content is $0.4 \%$, and then with the increase of fiber content Continued growth, the dynamic stability began to decrease. The test results show that for improving the high temperature performance of the asphalt mixture, the best content of mineral fiber exists. When the optimum dosage is exceeded, the stability begins to decline. This is because excess fiber can not be fully dispersed in the asphalt mixture. Only when the fiber Dispersed evenly in order to play a stabilizing role of asphalt mixture, some uneven dispersion of fibers can lead to bundles of phenomena, thereby reducing the mineral fiber reinforcement and adhesion.From Fig. 1, we also can see that the asphalt mixture with $0.4 \%$ of the best dosage of mineral No. 2 and No.3 showed the rutting dynamic stability better than the $0.3 \%$ of the best wood fiber. While the best dosage was $0.4 \%$ Asphalt mixture No.4 is not as good as the best dosage of $0.3 \%$ wood fiber asphalt mixture at high temperature stability.

Low Temperature Bending Test

In the case of meeting the best oil asphalt-aggregate ratio, the maximum bending failure strain index in low temperature bending test was used to evaluate the low temperature crack resistance of SMA-13 asphalt mixture ${ }^{[8]}$. Four groups of low-temperature bending tests were conducted on different fibers at different dosages. The test results were averaged. The results are presented in Tab.2. 
Tab.2 SMA-13 low temperature bending test results

\begin{tabular}{c|c|c|c|c}
\hline Fiber type & $\begin{array}{c}\text { Fiber } \\
\text { content }(\%)\end{array}$ & $\begin{array}{c}\text { Maximum } \\
\text { load }(\mathrm{N})\end{array}$ & $\begin{array}{c}\text { Maximum bending } \\
\text { strain }(\mu \varepsilon)\end{array}$ & $\begin{array}{c}\text { Flexural stiffness } \\
\text { modulus }(\mathrm{MPa})\end{array}$ \\
\hline Wood fiber & 0.3 & 1616 & 3562.8 & 3680.57 \\
\hline \multirow{2}{*}{$\begin{array}{c}\text { No. } 2 \text { mineral } \\
\text { fiber }\end{array}$} & 0.3 & 1512 & 3389.6 & 3599.89 \\
\cline { 2 - 5 } & 0.4 & 1654 & 3662.9 & 3701.24 \\
\hline \multirow{2}{*}{$\begin{array}{c}\text { No. } 3 \text { mineral } \\
\text { fiber }\end{array}$} & 0.5 & 1618 & 3588.6 & 3681.08 \\
\cline { 2 - 5 } & 0.3 & 1545 & 3496.4 & 3658.23 \\
\hline \multirow{2}{*}{$\begin{array}{c}\text { No. } 4 \text { mineral } \\
\text { fiber }\end{array}$} & 0.4 & 1709 & 3789.4 & 3825.14 \\
\cline { 2 - 5 } & 0.5 & 1690 & 3654.5 & 3784.24 \\
\hline
\end{tabular}

From the analysis of the test results in Table 2, it can be seen that under the same fiber content, The maximum load, maximum flexural strain and stiffness modulus of the mixture added with mineral 3 asphalt mixture are the largest, low temperature crack resistance is the best. The test results show that after the optimum content of mineral fiber is blended, the strength and deformation capacity of the asphalt mixture are improved, showing the characteristics of high modulus and strength. The fiber stabilizer gives full play to the bridging effect, increases the anti-deformation capacity of the asphalt mixture, and also significantly increases the maximum flexural tensile strength and stiffness modulus, thereby greatly improving the low-temperature performance of the asphalt mixture.

It can be seen from Table 2 that the best flexural strength, maximum load and stiffness modulus of asphalt mixture with $0.4 \%$ mineral 2 and mineral 3 than that with $0.3 \%$ wood fiber are the best, low temperature crack resistance is better; The best content of $0.4 \%$ mineral No.4 asphalt mixture than the best dosage of $0.3 \%$ wood fiber asphalt mixture at low temperature cracking performance is worse.

Water Stability Test

The freeze-thaw splitting test was used to evaluate the water stability of SMA-13 asphalt mixture under the condition of meeting the best oil asphalt-aggregate ratio ${ }^{[9]}$.Four different water stability tests were conducted on different fibers at different dosages. The test results were averaged. The results are shown in Fig.2.

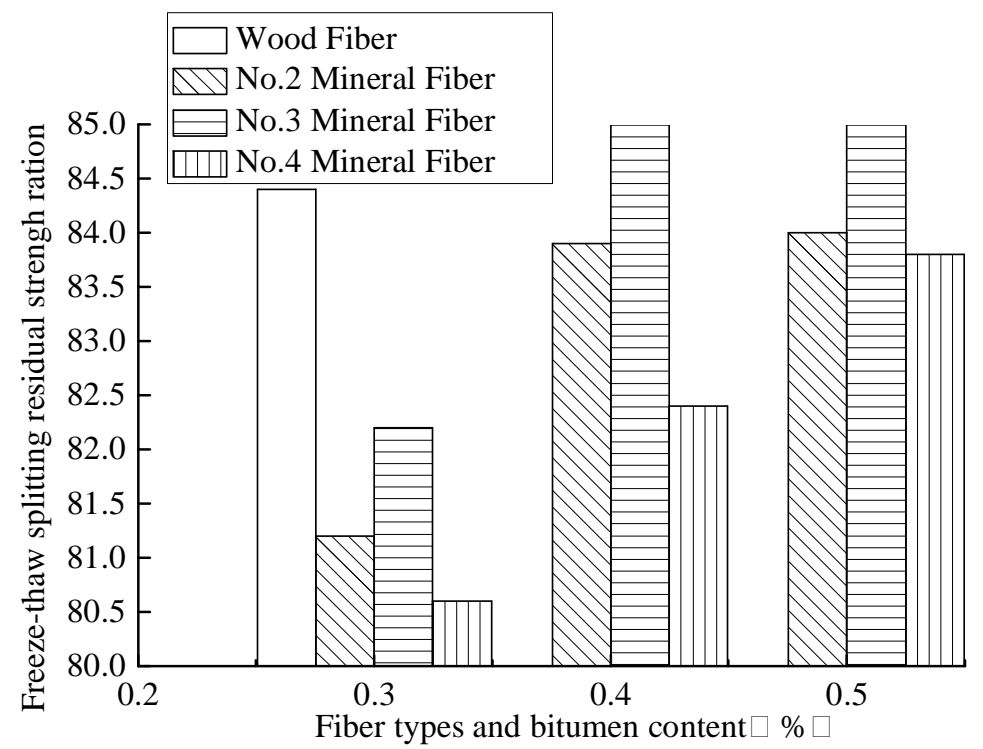

Fig.2 SMA-13 freeze-thaw splitting test results 
As can be seen from the experimental data in Fig.2, the asphalt mixture with $0.4 \% \sim 0.5 \%$ mineral 3 is better than the asphalt with $0.3 \%$ wood fiber in the Freeze-thaw splitting residual ratio, the water stability is better. The asphalt mixture of $0.3 \%$ wood fiber is better than the asphalt mixture with No.2 and No.4 mineral admixtures. The comparison of three kinds of mineral fiber shows that under the same fiber content, the mineral stability of No.3 asphalt mixtures is the best, followed by No.2 and No.4 is the worst. Analysis shows that the addition of fiber increases the optimal asphalt content of asphalt mixture, the effective asphalt film thickness of mineral aggregate and the adhesion of asphalt mortar to mineral materials are increased, which it effectively weakens the effect of water on the interface between the asphalt and the mineral material. Under the action of fiber reinforcement and adsorption, Asphalt and mineral materials between the interface will be enhanced, and the performance of different fiber asphalt mixtures will be improved to some extent. In contrast, wood fiber freeze-thaw splitting strength is relatively large.

Schellingborg Leak Test and Kentucky Scattered Test

The asphalt content and the presence and function of fiber in SMA-13 asphalts were measured using the Scattering test from Fort Schaumburg and the scattering rates and leak losses from the Kentucky Fly-ash test ${ }^{[10]}$, four different concentrations of different fibers were made under the analysis of leakage spatter test, the test results averaged, the results shown in Table 3.

Tab.3 SMA-13 leak scattering analysis results

\begin{tabular}{c|c|c|c|c|c|c|c|c|c|c|c}
\hline Fiber type & WoodFiber & \multicolumn{2}{|c|}{ No.2 mineral fiber } & \multicolumn{2}{c}{ No.3 mineral fiber } & \multicolumn{3}{c}{ No.4 mineral fiber } \\
\hline Fiber content(\%) & 0.3 & 0.3 & 0.4 & 0.5 & 0.3 & 0.4 & 0.5 & 0.3 & 0.4 & 0.5 \\
\hline $\begin{array}{c}\text { Sherlenburg } \\
\text { asphalt leak(\%) }\end{array}$ & 0.02 & 0.05 & 0.03 & 0.04 & 0.06 & 0.04 & 0.05 & 0.06 & 0.05 & 0.06 \\
\hline $\begin{array}{c}\text { Fort Kentburg } \\
\text { Flew(\%) }\end{array}$ & 2.6 & 3.1 & 2.8 & 2.9 & 2.9 & 2.6 & 2.1 & 3.2 & 2.8 & 2.8 \\
\hline
\end{tabular}

From the analysis of the test data in Table 3, it can be seen that the asphalt mixture of $0.3 \%$ wood fiber has the lowest loss of seepage and scattering. The horizontal comparison of the three kinds of mineral fibers shows that when the content of mineral fiber is $0.4 \sim 0.5 \%$, seepage loss and scattering loss of asphalt mixture are less. When the fiber content was increased, the optimum asphalt content will increase gradually, but the loss of seepage and scattering loss will decrease and then increase, indicating that the fiber has good adhesion to the asphalt, but with the fiber doping the amount of fiber increases, the fibers can not be uniformly dispersed in the asphalt, resulting in the adhesion of asphalt on the aggregate decreased, thereby increasing the loss of asphalt seepage and scattering loss.

\section{Conclusion}

By comparing the performance of different fiber SMA-13 road performance test, the following conclusions can be drawn:

(1) Marshall test and scatter test of asphalt mixture with different fiber content of different fibers shows that the oil absorption of wood fibers is stronger than that of mineral fibers. Three kinds of mineral fibers horizontal comparison shows that, in the same fiber content, mineral No.3 has the best oil absorption.

(2) Through the performance test of different fibers in asphalt mixture with different dosage, It can be concluded that the asphalt mixture with the content of $0.4 \sim 0.5 \%$ mineral 3 is better than the asphalt mixture with the content of $0.3 \%$ wood fiber in high and low temperature stability and water stability, road performance is better. The horizontal comparison of the three kinds of mineral fibers shows that asphalt mixture with mineral No.3 is the best road performance at the same fiber content.

(3) According to the test of road performance of asphalt mixture with the best content of different fibers, the content of fiber in asphalt mixture has the best value. When the content of fiber is too small, Too little fiber content can not play a reinforcing role. Too much fiber in the asphalt caused uneven dispersion of the road performance degradation. 


\section{References}

[1] Reed B F, James L Burat J R. Polyester Fibers in Asphalt Paving Mixtures. Journal of the Association of Asphalt Paving Technologists. 1996, 65(1):65 66.

[2] Mayajit Mazumdar, Mahabir Panda. Utilization of Reclaimed Polyethylene in Bituminous Paving Mixes. Journal of Materials in Civil Engineering. 2002, 14(6): 527 530.

[3] Harris B M, Stuart K D. Analysis of Mineral Fillers and Mastics used in Stone Matrix Asphalt. Journal of the Association of Asphalt Paving Technologists. 1995, 64(1):211 234.

[4] Kietzman J H. Performance of Asbestos-asphalt Pavement Surface Course with High Asphalt Contents. Highway Research Record. 1963, 12(14):153 168.

[5] Technical Specification for Asphalt Pavement Construction [S] .JTG F40-2004. Beijing: China Communications Press, 2004.

[6] Gao J. Application of mineral fibers in SMA-13 asphalt pavement [D] .Jiangsu Jiaotong University, 2013.

[7] An Wang. Basalt fiber SMA-13 road performance research and application [D]. Changsha University of Science and Technology, 2013.

[8] Wenxiao Fan. Experimental study on the performance of basalt fiber reinforced pavement materials [D]. Dalian University of Technology, 2011.

[9] Huadong Li, Wenting Dai. Mineral fiber asphalt mixture in the optimal dosage of fiber [J], Highway, 2014,14 (25): 288-292.

[10] Yanhai Yang, Wen Zhao, Yuhui Wu. Evaluation of water damage resistance of recycled asphalt mixture [J] .Journal of Highway and Transportation Research and Development, 2006,07: 1 